\title{
Effects of Uncrushed Aggregate on the Mechanical Properties of No-Fines Concrete
}

\author{
Muneeb Ayoub Memon \\ Department of Civil Engineering \\ Quaid-e-Awam University of Engineering, \\ Science \& Technology \\ Nawabshah, Pakistan \\ engr.muneebmemon@gmail.com
}

\author{
Muhammad Aslam Bhutto \\ Department of Civil Engineering \\ NED University of \\ Engineering \& Technology \\ Karachi, Pakistan \\ mabhutto@neduet.edu.pk
}

\author{
Nawab Ali Lakho \\ Department of Civil Engineering \\ Quaid-e-Awam University of \\ Engineering, Science \& Technology \\ Nawabshah, Pakistan \\ nawablakho@gmail.com
}

\author{
Imtiaz Ali Halepoto \\ Department of Computer Systems Engineering \\ Quaid-e-Awam University of \\ Engineering, Science \& Technology \\ Nawabshah, Pakistan \\ halepoto@quest.edu.pk
}

\author{
Ammaar Noor Memon \\ Department of Civil Engineering \\ Quaid-e-Awam University of \\ Engineering, Science \& Technology \\ Nawabshah, Pakistan \\ anmemon96@gmail.com
}

\begin{abstract}
Concrete's self-weight is a major aspect of a structure's overall weight. Recently, the use of lightweight concrete (no-fines, foamed and cellular concrete) has been increased. Normally no-fines concrete is produced with crushed coarse aggregate of uniform gradation. This study aims to investigate experimentally the effects of the use of uncrushed coarse aggregates on unit weight, compressive and tensile strength of the no-fines (NFC) as well as conventional concrete (CC). In addition, the effects of coarse aggregate size on the mechanical properties were also studied. Four gradations of uncrushed coarse aggregates ranging between $(5.5-4.75) \mathrm{mm},(10-$ 4.75) $\mathrm{mm},(20-4.75) \mathrm{mm}$ and (25-4.75) $\mathrm{mm}$ were used for preparing the concretes. The fixed cement-aggregate ratios of $1: 6$ (with w/c ratio $=0.4$ ) and 1:2:4 (with w/c ratio $=0.5$ ) were adopted for NFC and CC respectively. It was found that the gradation of uncrushed coarse aggregate has a significant effect on the mechanical properties of NFC. A maximum of $16 \%$ reduction in self-weight of the concrete without fines was obtained, as compared to that with fines. Moreover, the compressive strength of no-fines concrete significantly improved by replacing crushed with uncrushed coarse aggregate. The compressive strength increased by $16 \%$ for the batch of $(25-4.75) \mathrm{mm}$.
\end{abstract}

Keywords-no-fines concrete; uncrushed aggregate; unit weight; compressive strength

\section{INTRODUCTION}

The self-weight of concrete is a major aspect of the overall weight of the structure. The lightweight concrete with sufficient strengths can be used for partition walls in framed structure, road pavings etc [1]. No-fines concrete is categorized as lightweight concrete. The no-fines concrete (NFC) is cast by mixing cement and only coarse aggregate [2]. The behaviour of NFC has been investigated by some researchers. Authors in [3] replaced coarse and fine aggregates with clay and used aluminum-wastage as foaming agent for cement. In addition, compressive strength and thermal conductivity of no-fines cellular concrete were investigated. Authors in [4] carried out an experimental study to determine the compressive strength of structural lightweight concrete by non-destructive ultrasonic pulse velocity method. They found that lightweight concretes with less porous aggregates are associated with lower ultrasonic pulse velocity and vice versa. Authors in [5] experimented on the use of no-fines concrete as a building material and determined strength, durability properties of nofines concrete and checked corrosion protection of the embedded steel. They concluded that no-fines concrete could also be used in non structural elements such as reinforced panels. Authors in [6] investigated some properties of no-fines polymer concrete, using $10 \mathrm{~mm}$ maximum size of coarse aggregates. Several concrete mixes with different cement aggregate ratios like 1:5, 1:6 and 1:7 were produced. The polymer was mixed in percentages by weight of cement as $5 \%$, $7 \%$ and $10 \%$. It was found that the density of no-fines concrete varies between 2030 and $2170 \mathrm{~kg} / \mathrm{m}^{3}$ and thermal conductivity was in the range recommended by ACI 213-87 for structural lightweight concrete. Author in [7] studied the hardened properties of no-fines concrete and used it as a lightweight concrete block masonry unit. In this study three different aggregate/cement ratios of $6: 1,8: 1$ and $10: 1$ and three different $\mathrm{w} / \mathrm{c}$ ratios of $0.35,0.4$ and 0.45 have been used to determine the compressive strength, flexural strength and split tensile strength of NFC. Results showed that for building application aggregate-cement ratio of $6: 1 \mathrm{mix}$ at $0.45 \mathrm{w} / \mathrm{c}$ ratio is recommended. Their 28 day compressive strength was found more when compared to other mixes, while the split tensile and flexural strength of no-fines concrete was found to range. Authors in [8] carried out an experimental study to investigate 
the performance of no-fines concrete in terms of compressive strength, porosity and permeability. The effect of aggregate gradation and use of fine aggregate in the mix proportion was also studied to evaluate the performance. The well graded sample was found suitable among various types of gradation. After that $0 \%, 2 \%, 4 \%, 6 \%, 8 \%$ and $10 \%$ fine aggregate (sand) was added in the well graded sample having water/cement ratio and aggregate/cement ratio 0.40 and 4.5:1, respectively. It was found that the addition of fine aggregate (sand) up to $10 \%$ increased the compressive strength about $56 \%$ but decreases porosity and permeability about $85 \%$ and $76 \%$, respectively. Author in [9] investigated the mechanical characteristics of nofines concrete with or without polypropylene fibers. The studied properties were unit-weight, compressive strength and tensile strength. Results showed that the addition of polypropylene fibers in no-fines concrete can improve mechanical properties, especially tensile strength and compressive strength by $19 \%$ and $17 \%$ respectively compared with the concrete without fibers, with a slight effect on density. It was found that the strength of no-fines concrete is strongly related to its mixture proportion

Although sufficient research has been carried out to investigate the behavior of no-fines concrete, yet no attempt has been made to investigate experimentally the strength properties and unit weight of no-fines concrete with uncrushed aggregates. Uncrushed aggregate is a waste obtained from the sieving of fine hill sand. The usage of waste in no-fines concrete makes it more economical when compared to conventional concrete. In view of the aforementioned issues, this study aims at investigating the effects of uncrushed coarse aggregate on unit weight, compressive and tensile strength of the no-fines (i.e. lightweight) concrete (NFC). In addition the effects of coarse aggregate size on mechanical properties were studied. Compressive and tensile strength tests in specimens cast from four different batches of coarse aggregates were conducted. The results of NFC were compared with that of conventional concrete.

\section{EXPERIMENTAL PART}

\section{A. Materials and Mix Proportions of Concrete}

Ordinary Portland cement (OPC) as per standard of ASTM $\mathrm{C} 150$ was used to prepare NFC and conventional concrete mix. To prepare conventional concrete mix design, locally available hill sand (i.e. passed from No. 16 sieve) was used. The hill sand was complying with ASTM C 778-02 (2002) and its gradation was according to specifications of ASTM C 33-03 (2003). The retained hill sand from No. 16 sieve was used as coarse aggregate for preparation of both no-fines and conventional concrete. The retained uncrushed coarse aggregates were smooth in surface texture. The smoothness of the coarse aggregates improves workability of both concretes. These different particle size aggregates were passed from different sizes of sieves (i.e. $4.75,5.5,10,20$ and $25 \mathrm{~mm}$ ) to obtain different batches of coarse aggregates. Four different batches were formed ranging from 4.75 to $5.5 \mathrm{~mm}$, from 4.75 to $10 \mathrm{~mm}$, from 20 to $5.5 \mathrm{~mm}$ and from 25 to $5.5 \mathrm{~mm}$. To be more specific, the aggregates retained in $4.75 \mathrm{~mm}$ sieve and passed from 5.5 $\mathrm{mm}$ sieve in the first batch (from 4.75 to $5.5 \mathrm{~mm}$ ). All the batches of the coarse aggregates are summarized in Table I. Tap water (suitable for drinking) was used while preparing conventional and no-fines concrete. A mixed proportion of 1:6 (cement: coarse aggregate) was used for the preparation of nofines concrete. Whereas conventional concrete was prepared from a mixed proportion of 1:2:4 (cement: fine aggregate: coarse aggregate).

TABLE I. BATCHES OF COARSE AGGREGATES

\begin{tabular}{|c|c|c|}
\hline S. No. & Batch designation & Description \\
\hline 01 & NFC / CC (5.5-4.75) & $\begin{array}{c}\text { Un-crushedcoarse aggregates of size } \\
5.5 \mathrm{~mm} \text { to } 4.75 \mathrm{~mm}\end{array}$ \\
\hline 02 & NFC / CC (10-4.75) & $\begin{array}{c}\text { Un-crushed coarse aggregates of size } \\
10 \mathrm{~mm} \text { to } 4.75 \mathrm{~mm}\end{array}$ \\
\hline 03 & NFC / CC (20-4.75) & $\begin{array}{c}\text { Un-crushed coarse aggregates of size } \\
20 \mathrm{~mm} \text { to } 4.75 \mathrm{~mm}\end{array}$ \\
\hline 04 & NFC / CC (25-4.75) & $\begin{array}{c}\text { Un-crushed coarse aggregates of size } \\
25 \mathrm{~mm} \text { to } 4.75 \mathrm{~mm}\end{array}$ \\
\hline
\end{tabular}

\section{B. Specimen Preparation}

Cubes of conventional and NFC with standard size $150 \mathrm{~mm}$ x $150 \mathrm{~mm} \times 150 \mathrm{~mm}$ were prepared for compressive strength measurement of both concretes. For measuring tensile strength, cylinders of $100 \mathrm{~mm}$ diameter and $200 \mathrm{~mm}$ length were cast. In order to check accuracy and repeatability of the tests results, five specimens of each of cubes and cylinders were cast from each batch of coarse aggregates. Cubic and cylindrical moulds made of steel were used to cast the specimens. The prescribed concrete mixes (i.e. 1:6 and 1:2:4 for no-fines and conventional concretes, respectively) were prepared from each batch of coarse aggregates. After each mix preparation, the concrete was poured into cubic and cylindrical steel moulds. Before pouring, a thin oil layer was applied to the inside surfaces of the mould in order to prevent the bond development between the mould and the concrete. The conventional concrete was poured into moulds in three layers and then was compacted using vibration table. However, the NFC was poured in one layer and without compaction. The specimens were then demoulded after 24 hours curing in a controlled indoor environment. Next, the samples were kept in a water tank for curing at $27 \pm 1^{\circ} \mathrm{C}$ until testing. Some specimens of NFC are shown in Figures 1 and 2.

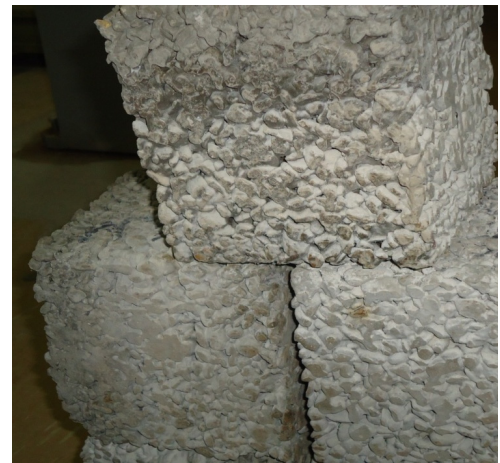

Fig. 1. Demoulded cubes of NFC 


\section{Test Methods}

Before the specimens of no-fine and conventional concrete were tested for compressive and split tensile strength, each specimen's unit weight was determined. All the specimens were weighed to calculate the unit weight before testing. To determine compressive strength, the cubes were tested in a universal testing machine (UTM). The cubes were placed with the cast faces in contact with platens of the testing machine as shown in Figure 3. Then, the compressive load was applied gradually. Because of the non-linearity in the behavior of the concrete, the strain rate was increased progressively as failure was approached. The ultimate load at the crushing failure of cube specimens was recorded. The load is divided by the cross sectional area of the cube to determine the ultimate compressive strength. As mentioned in section B, five specimens of cubes of each of no-fines and conventional concrete were cast from each batch. The ultimate compressive strength of each of the five specimens was measured. The average of the five values represents the ultimate strength of the cubes of their respective batch. Cylinder tests were performed to determine the tensile strength of no-fines and conventional concrete. In this test the concrete cylinders were placed with their horizontal axis between the platens of the UTM (Figure 3) and the load increased until failure by indirect tension in the form of splitting along vertical diameter took place. At cylinder failure, the ultimate load was recorded and tensile strength was calculated from (1)

$$
f_{1}=2 P / 3.14 L D
$$

where $f_{l}=$ tensile strength, $P=$ ultimate applied load $L=$ cylinder length and $D=$ cylinder diameter.

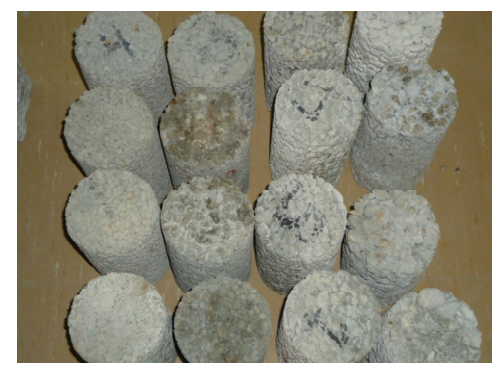

Fig. 2. Demoulded cyliders of NFC

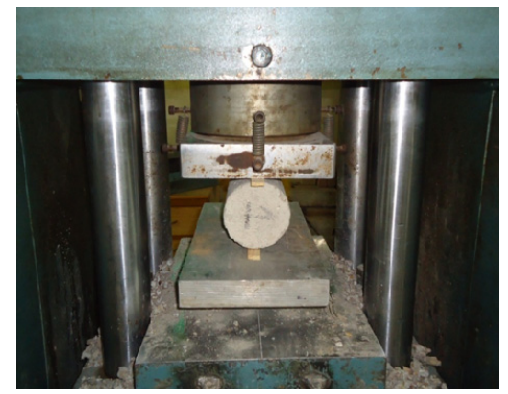

Fig. 3. A cyliderical specimen placed in UTM

\section{RESULTS AND DISCUSSION}

\section{A. Unit Weight}

The unit weight of each specimen of no-fines and conventional concretes was calculated before compressive and tensile strength tests. The average unit weight is given in Table II. It can be observed that the unit weight of the batch with larger size of uncrushed coarse aggregate was higher. For the batch $25-4.75 \mathrm{~mm}$, the maximum unit weight was $2152 \mathrm{~kg} / \mathrm{m}^{3}$ and $2527 \mathrm{~kg} / \mathrm{m}^{3}$ for no-fines and conventional concrete, respectively. Figure 4 compares the unit weight of NFC with crushed and coarse aggregates. The unit weight of NFC with crushed aggregates for each batch was measured in [1]. It can be seen that NFC with uncrushed coarse aggregates is lighter than the NFC with crushed aggregates. The maximum 2152 $\mathrm{kg} / \mathrm{m}^{3}$ and minimum $2038 \mathrm{~kg} / \mathrm{m}^{3}$ unit weight of NFC with uncrushed coarse aggregates were measured for the batch of $5.5-4.75 \mathrm{~mm}$ and $25-4.75 \mathrm{~mm}$ respectively. The NFC with uncrushed coarse aggregates prepared from batch $5.5-4.75 \mathrm{~mm}$ is $13 \%$ lighter than that with crushed coarse aggregates. Figure 5 illustrates the comparison of the unit weight of no-fine concrete with that of conventional concrete for each batch with uncrushed coarse aggregates. It can be seen that the unit weight of the NFC is less than that of conventional concrete. This implies that the NFC is lighter than the conventional concrete. The NFC from batch $5.5-4.75 \mathrm{~mm}$ was found to be $20 \%$ lighter than conventional concrete.

TABLE II. AVERAGE UNIT WEIGHT

\begin{tabular}{|c|c|c|c|}
\hline \multirow{2}{*}{ S. No. } & \multirow{2}{*}{ Batch designation } & \multicolumn{2}{|c|}{ Average unit weight $(\mathrm{kg} / \mathrm{m} 3)$} \\
\hline & & $\begin{array}{l}\text { No-fines } \\
\text { concrete }\end{array}$ & $\begin{array}{c}\text { Conventional } \\
\text { concrete }\end{array}$ \\
\hline 01 & NFC / CC (5.5-4.75) & 2038.4 & 2426.64 \\
\hline 02 & NFC / CC (10-4.75) & 2059.11 & 2451.95 \\
\hline 03 & NFC / CC (20-4.75) & 2143.98 & 2522.62 \\
\hline 04 & NFC / CC (25-4.75) & 2152.26 & 2527.34 \\
\hline
\end{tabular}

\section{B. Compresive Strength}

Figure 6 shows the compressive strength of NFC with crushed and uncrushed coarse aggregate after 28 days. Author in [1] measured the compressive strenght of NFC with crushed coarse from cubes after 28 days. Therefore, a direct comparision can be made. It can be seen from the figure that NFC with uncrushed aggregate gives higher compressive strength than the concrete with crushed aggregate in each batch. The maximum compressive strength of was measured in the batch of $25-4.75 \mathrm{~mm}$. The magnitude of the maximum compressive strength is $10 \mathrm{MPa}$ which is $16 \%$ higher than that with uncrushed coarse aggregates. Furthermore the size of coarse aggregates has significant effect on the compressive strength of no-fines concrete. The compressive strength increases with coarse aggregate size. The percentage increment of compressive strength of batch $25-4.75 \mathrm{~mm}$ is 110 when compared to the strength of NFC of batch $5.5-4.75 \mathrm{~mm}$. Figure 7 illustrates the compressive strength of NFC with uncrushed coarse aggregate and $\mathrm{CC}$ after 28 days. It can be observed that the strength of $\mathrm{CC}$ reduces significantly without fine aggregates (i.e. no-fines concrete). A maximum reduction of $72 \%$ was 
measured. However, the compressive strength of both concretes increases with the increment of coarse aggregates size. This is the reason the NFC is used in non-structural applications (such as paving).

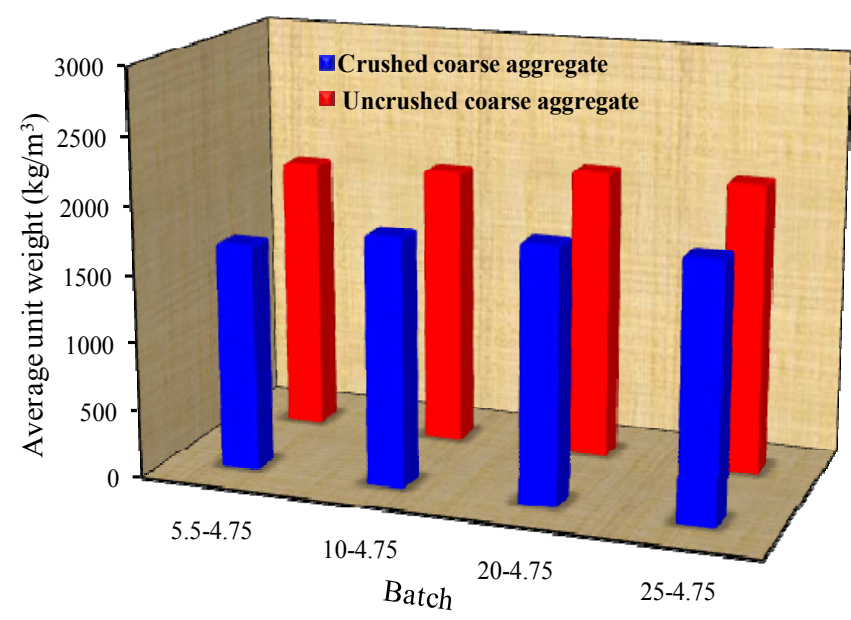

Fig. 4. Unit weight of NFC with crushed and uncrushed coarse aggregate

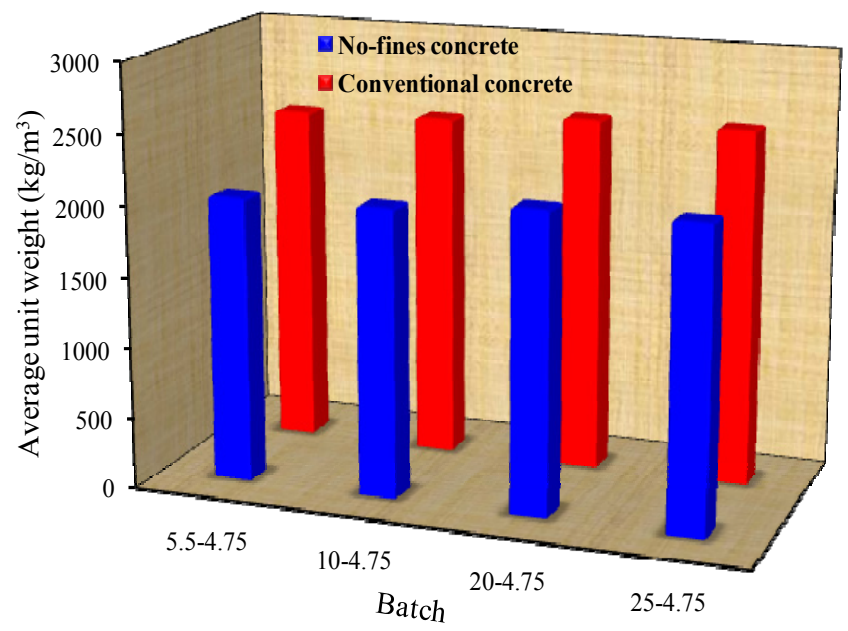

Fig. 5. Unit weight of NFC and CC with uncrushed coarse aggregate

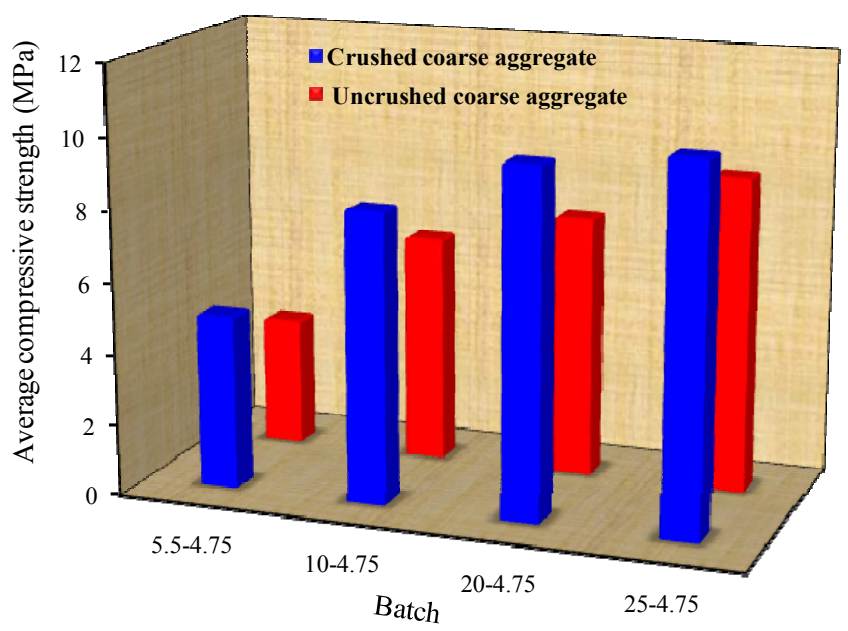

Fig. 6. Compressive strength of NFC with crushed and uncrushed coarse aggregate

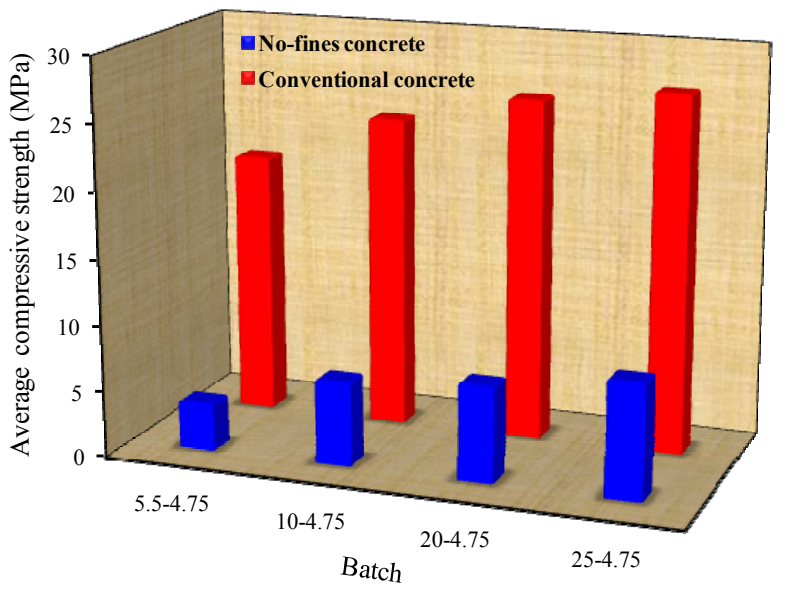

Fig. 7. Compressive strength of NFC and $\mathrm{CC}$ with uncrushed coarse aggregate

\section{Compressive and Tensile Strength}

Figure 8 compares the compressive and tensile strength of NFC with uncrushed aggregates for all batches. It can be seen that the tensile strength is much smaller than the compressive strength of NFC for all batches. However, it is observed that tensile strength is same for all batches. It implies that the tensile strength is independent of the size of coarse aggregate in NFC. The maximum difference (i.e. $84 \%$ smaller) between tensile strength and compressive strength was found in the 25$4.75 \mathrm{~mm}$ batch. 


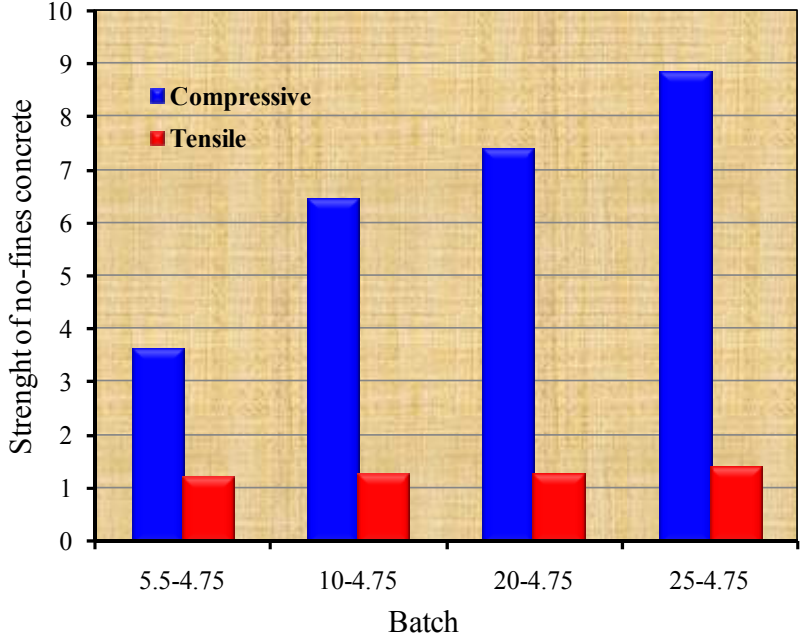

Fig. 8. Comparision of compressive and tensile strength NFC with uncrushed coarse aggregate

Similar to compressive strength, the tensile strength of NFC is lower than that of conventional concrete with uncrushed coarse aggregates (as shown in Figure 9). However, tensile strength of conventional concrete increased with the size of uncrushed coarse aggregates. For the batch $25-4.75 \mathrm{~mm}$, the tensile strength of NFC was measured $68 \%$ less than that of conventional concrete.

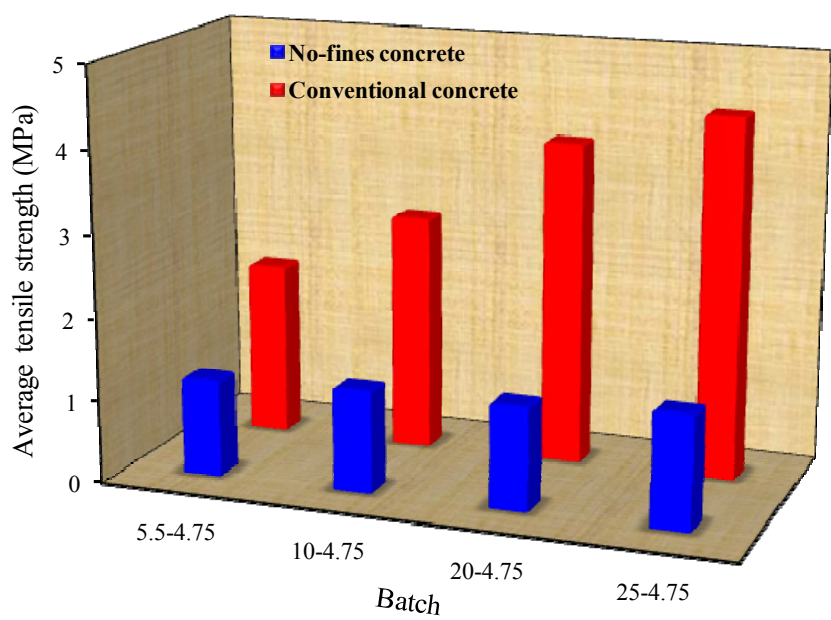

Fig. 9. Comparision of tensile strength of NFC and CC with uncrushed coarse aggregate

\section{CONCLUSION}

The compressive strength of NFC is significantly improved by replacing crushed with uncrushed coarse aggregate. The compressive strength increased by $16 \%$ for the $25-4.75 \mathrm{~mm}$ batch. On the contrary, the unit weight of the NFC with uncrushed aggregate decreased compared to that with uncrushed coarse aggregates. However, a maximum reduction percentage of $72 \%$ was achieved in compressive strength of the concrete without fines. The NFC with uncrushed coarse aggregates prepared from the $5.5-4.75 \mathrm{~mm}$ batch is $13 \%$ lighter than that with crushed coarse aggregates. The tensile strength of both concretes is in agreement with the standard values reported in the literature (i.e. $5 \%$ to $15 \%$ of respective compressive strength). The tensile strength of NFC was measured $20 \%$ of that of compressive strength.

\section{ACKNOWLEDGMENT}

Authors are grateful to the Quaid-e-Awam University of Engineering, Science and Technology, Nawabshah for providing the research facilities.

\section{REFERENCES}

[1] Z. A. Tunio, Experimental Investigation of Strength of No-fines Concrete with various course aggregate gradation, M.E, Quaid-e-Awam Univeristy of Engineering Scince \& Technology, 2015

[2] N. Newman, P. Owens, "Properties of lightweight concrete". In Newman, J. and Choo, B.S. (eds.) Advanced Concrete Technology, Butterworth-Heinemann, 2003

[3] C. J. Chang, Y. C. Chang, "Extra-Lightweight No-fines cellular concrete-use for non-structural material", Advanced Material Research, Vol. 834-836, pp. 713-716, 2014

[4] J. A. Bogas, M. G. Gomez, A. Gomes, "Compressive Strength Evaluation of Structural Lightweight Concrete by Non-destructive Ultrasonic Plus Velocity Method", Ultrasonics, Vol. 53, No. 5, pp. 962972, 2013

[5] M. Carsana, F. Tittarelli, L. Bertolini, "Use of No-Fines concrete as a Building Materials: Strength, Durability Properties and Corrosion protection of embedded steel", Cement and Concrete Research, Vol. 48, pp. 64-73, 2013

[6] A. K. I. Al-Hadithi, S. B. Al-Nu'man, I. A. Al-Jumaily, "Some properties of No-fines Polymer concrete", Journal of Engineering and Development, Vol. 11, No. 3, pp. 1-13, 2013

[7] A. Malik, "An Experimental Study on Properties of No-Fines Concrete", Imperial Journal of Interdisciplinary Research (IJIR), Vol. 2, No. 10, pp. 2075-2079, 2016

[8] M. A. Kabir, K. M. S. Islam, "Performance study on no fines concrete", 3rd International Conference on Civil Engineering for Sustainable Development (ICCESD), KUET, Khulna, Bangladesh, 2016

[9] A. A. Muttar, "Improving The Mechanical Properties of No- Fines Concrete", Journal of Babylon University/ Engineering Sciences, Vol. 21, No. 2, 2013 